\title{
12/15-Lipoxygenase inhibition counteracts MAPK phosphorylation in mouse and cell culture models of diabetic peripheral neuropathy
}

\author{
Roman Stavniichuk ${ }^{1}$, Alexander A. Obrosov ${ }^{1}$, Viktor R. Drel ${ }^{1}$, Jerry L. Nadler ${ }^{2}$, \\ Irina G. Obrosova ${ }^{1}$, Mark A. Yorek ${ }^{3^{*}}$ \\ ${ }^{1}$ Pennington Biomedical Research Center, Louisiana State University System, Baton Rouge, USA \\ ${ }^{2}$ Department of Internal Medicine, Eastern Virginia Medical School, Norfolk, USA \\ ${ }^{3}$ Department of Veterans Affairs Iowa City Health Care System and Department of Internal Medicine, University of Iowa, Iowa City, \\ USA; ${ }^{*}$ Corresponding Author: mark-yorek@uiowa.edu
}

Received 14 May 2013; revised 16 June 2013; accepted 23 June 2013

Copyright (C) 2013 Roman Stavniichuk et al. This is an open access article distributed under the Creative Commons Attribution License, which permits unrestricted use, distribution, and reproduction in any medium, provided the original work is properly cited.

\section{ABSTRACT}

Background: Increased mitogen-activated protein kinase (MAPK) phosphorylation has been detected in peripheral nerve of human subjects and animal models with diabetes as well as high-glucose exposed human Schwann cells, and have been implicated in diabetic peripheral neuropathy. In our recent studies, leukocytetype 12/15-lipoxygenase inhibition or gene deficiency alleviated large and small nerve fiber dysfunction, but not intraepidermal nerve fiber loss in streptozotocin-diabetic mice. Methods: To address a mechanism we evaluated the potential for pharmacological 12/15-lipoxygenase inhibition to counteract excessive MAPK phosphorylation in mouse and cell culture models of diabetic neuropathy. C57BI6/J mice were made diabetic with streptozotocin and maintained with or without the 12/15-lipoxygenase inhibitor cinnamyl-3,4-dihydroxy- $\alpha$-cyanocinnamate (CDC). Human Schwann cells were cultured in $5.5 \mathrm{mM}$ or $30 \mathrm{mM}$ glucose with or without CDC. Results: 12(S) HETE concentrations (ELISA), as well as 12/15-lipoxygenase expression and p38 MAPK, ERK, and SAPKIJNK phosphorylation (all by Western blot analysis) were increased in the peripheral nerve and spinal cord of diabetic mice as well as in high glucose-exposed human Schwann cells. CDC counteracted diabetes-induced increase in 12(S)HETE concentrations (a measure of 12/15-lipoxygenase activity), but not 12/15-lipoxygenase overexpression, in sciatic nerve and spinal cord. The inhibitor blunted excessive p38 MAPK and ERK, but not SAPKI JNK, phosphorylation in sciatic nerve and high glucose exposed human Schwann cells, but did not affect MAPK, ERK, and SAPKIJNK phosphorylation in spinal cord. Conclusion: 12/15lipoxygenase inhibition counteracts diabetes related MAPK phosphorylation in mouse and cell culture models of diabetic neuropathy and implies that 12/15-lipoxygenase inhibitors may be an effective treatment for diabetic peripheral neuropathy.

Keywords: Diabetes; Lipoxygenase; Neuropathy; Schwann Cells; Mitogen-Activated Protein Kinase

\section{INTRODUCTION}

Diabetic peripheral neuropathy (DPN), affects at least $50 \%$ of patients with both Type 1 and Type 2 diabetes, and is a leading cause of foot amputation [1-3]. DPN is manifested by motor (MNCV) and sensory (SNCV) nerve conduction velocity deficits as well as microvascular dysfunction and by increased vibration and thermal perception thresholds that progress to sensory loss, occurring in conjunction with degeneration of all fiber types in the peripheral nerve [1-4]. A significant proportion of patients with DPN also describe abnormal sensations such as paresthesias, allodynia, hyperalgesia, and spontaneous pain [3]. The pathogenesis of DPN has extensively been studied in animal and cell culture models. Multiple biochemical changes have been attributed to the etiology of diabetic neuropathy including, but not limited to, increased activity of the sorbitol pathway [5-7], gen- 
eration of methylglyoxal $[8,9]$ and non-enzymatic glycation/glycoxidation [10,11], oxidative-nitrosative stress [12-16], impaired neurotrophic support [17,18], and activation of protein kinase C $[19,20]$, poly(ADP-ribose) polymerase [21,22], and of the enzymes of arachidonic acid metabolism, cyclooxygenase-2 [23] and leukocytetype 12/15-lipoxygenase [24,25]. Increased mitogenactivated protein kinase (MAPK) phosphorylation was detected in peripheral nerve of human subjects with diabetes [26], several animal models of diabetes [26-31], and high-glucose exposed cultured human Schwann cells [32], and has been implicated in the pathophysiology of diabetic peripheral neuropathy.

Multiple specific small molecule MAPK inhibitors are now in clinical trials for chronic diseases including several types of cancer, inflammatory and autoimmune diseases, neuropathic pain following nerve trauma, as well as Parkinson's and Alzheimer's diseases [33]. Regardless of these efforts and outcomes, the search for alternative approaches to inhibit excessive MAPK phosphorylation in specific pathological conditions including diabetic neuropathy is highly warranted. In our previous experiments [24,25,31], 12/15-lipoxygenase inhibition and gene deficiency improved several diabetic neuropathy associated endpoints in streptozotocin-diabetic mice including nerve conduction deficits and behavioral changes suggesting that preventing 12/15-lipoxygenase activation may be an effective treatment for diabetic neuropathy.

\section{MATERIALS AND METHODS}

\subsection{Reagents}

Unless otherwise stated, all chemicals were of reagent-grade quality, and were purchased from Sigma Chemical Co., St. Louis, MO, USA. Cinnamyl-3,4dihydroxy-alpha-cyanocinnamate (CDC) was obtained from Enzo Life Sciences International, Plymouth Meeting, PA, USA. For Western blot analyses in mouse tissues, rabbit polyclonal (clone H-100) anti-12-lipoxygenase (LO) antibody, rabbit polyclonal (clone H-147) anti-p38 MAPK antibody, mouse monoclonal (clone MK1) anti-ERK antibody, and rabbit polyclonal (clone C17) anti-JNK1 antibody were obtained from Santa Cruz Biotechnology, Santa Cruz, CA, USA. Rabbit polyclonal anti-phospho-p38 MAPK antibody, rabbit monoclonal (clone D13.14.4E) anti-phospho-ERK antibody, and rabbit polyclonal anti-phospho-SAPK/JNK antibody were purchased from Cell Signaling Technology, Boston, MA, USA. For Western blot analyses in human Schwann cells, rabbit polyclonal (clone $\mathrm{C} 16$ ) antibody against total ERK and mouse monoclonal (clone E4) antibody against phosphorylated ERK were obtained from Santa Cruz Biotechnology, Santa Cruz, CA. For other MAPKs, the antibodies listed above were used.

\subsection{Animals}

The experiments were performed in accordance with The Guide for the Care and Handling of Laboratory Animals (NIH Publication No. 85-23) and Pennington Biomedical Research Center Protocol for Animal Studies. Mature male C57B16/J mice were purchased from Jackson Laboratories. All the mice were fed standard mouse chow (PMI Nutrition International, Brentwood, MO, USA) and had ad libitum access to water. After a 7-day acclimation in a new environment, the mice were randomly divided into two groups. In one group, diabetes was induced by streptozotocin (STZ) as we described previously $[24,25]$. The mice with blood glucose $\geq 13.8$ $\mathrm{mM}$, three days post streptozotocin were considered diabetic. The control and diabetic mice were kept for 12 weeks without treatment, and then divided into two subgroups that were maintained with or without treatment with cinnamyl-3,4-dihydroxy- $\alpha$-cyanocinnamate (CDC), $8 \mathrm{mg} \mathrm{kg} / \mathrm{d}$, s.c., for another 4 weeks. CDC, at the aforementioned dose, counteracted multiple manifestations of diabetic neuroapthy and oxidative-nitrosative stress in peripheral nerve and spinal cord in our previous study [24]. Non-fasting blood glucose measurements were performed after induction of diabetes and at the end of the study period.

\subsection{Anesthesia, Euthanasia and Tissue Sampling}

The animals were sedated by $\mathrm{CO}_{2}$, and immediately sacrificed by cervical dislocation. Sciatic nerves and spinal cords were rapidly dissected and frozen in liquid nitrogen for subsequent assessment of LO as well as total and phosphorylated p38 MAPK, ERK, and SAPK/JNK levels, and 12(S)-HETE concentrations.

\subsection{Human Schwann Cell Culture}

Schwann cells play a key role in the pathology of various inflammatory, metabolic, and hereditary polyneuropathies, including diabetic neuropathy $[34,35]$. Previous studies demonstrated that cultured human Schwann cells (cell line cat. \#1700, ScienCell, Carlsbad, CA) manifest increased superoxide production, accumulation of nitrated and poly(ADP-ribosyl)ated proteins and 4hydroxynonenal adducts, inducible nitric oxide synthase overexpression, 12/15-Lipoxygenase overexpression and activation, increased p38 MAPK phosphorylation, downregulation of taurine transporter, as well as impaired insulin signaling early $(1-7 \mathrm{~d})$ after exposure to high glucose [24,36-38]. They therefore represent a good model for studying interactions among individual pathobiochemical mechanisms in the peripheral nerve. In the present study, human Schwann cells (passages 7 - 10) were cultured in 6-well plates in media containing 5.5 
$\mathrm{mM}$ D-glucose. At $\sim 70 \%$ confluence, the media were replaced with those containing either $5.5 \mathrm{mM}$ D-glucose or $30 \mathrm{mM}$ D-glucose with or without CDC, $10 \mu \mathrm{M}(6-8$ plates per condition). After $24 \mathrm{hr}$, the cells were used for assessment of total and phosphorylated p38 MAPK, ERK, and SAPK/JNK.

\subsection{Specific Methods}

\subsubsection{Western Blot Analyses of LO and Total and Phosphorylated p38 MAPK, ERK, and SAPK/JNK}

Sciatic nerve and spinal cord materials $(\sim 3-10 \mathrm{mg})$ or scraped human Schwann cells were placed on ice in 100 $\mu \mathrm{L}$ of buffer containing $50 \mathrm{mmol} / \mathrm{l}$ Tris- $\mathrm{HCl}, \mathrm{pH} 7.2 ; 150$ $\mathrm{mmol} / 1 \mathrm{NaCl} ; 0.1 \%$ sodium dodecyl sulfate; $1 \% \mathrm{NP}-40$; $5 \mathrm{mmol} / 1 \mathrm{EDTA} ; 1 \mathrm{mmol} / 1 \mathrm{EGTA} ; 1 \%$ sodium deoxycholate and the protease/ phosphatase inhibitors leupeptin $(10 \mu \mathrm{g} / \mathrm{ml})$, pepstatin $(1 \mu \mathrm{g} / \mathrm{ml})$, aprotinin $(20 \mu \mathrm{g} /$ $\mathrm{ml})$, benzamidine $(10 \mathrm{mM})$, phenylmethylsulfonyl fluoride $(1 \mathrm{mM})$, sodium orthovanadate $(1 \mathrm{mmol} / \mathrm{l})$, and homogenized on ice. The homogenates were sonicated and centrifuged at 14,000 g for $20 \mathrm{~min}$. All the afore-mentioned steps were performed at $4{ }^{\circ} \mathrm{C}$. The lysates $(20 \mu \mathrm{g}$ protein for sciatic nerve and $40 \mu \mathrm{g}$ for spinal cord and human Schwann cells) were mixed with equal volumes of 2x sample-loading buffer containing $62.5 \mathrm{mmol} / 1$ Tris$\mathrm{HCl}, \mathrm{pH} 6.8 ; 2 \%$ sodium dodecyl sulfate; $5 \% \beta$-mercaptoethanol; $10 \%$ glycerol, and $0.025 \%$ bromophenol blue, and fractionated in $10 \%$ (total and phosphorylated MAPKs) or 7.5\% (lipoxygenase) SDS-PAGE in an electrophoresis cell (Mini-Protean III; Bio-Rad Laboratories, Richmond, CA). Electrophoresis was conducted at 15 $\mathrm{mA}$ constant current for stacking, and at $25 \mathrm{~mA}$ for protein separation. Gel contents were electrotransferred (80 $\mathrm{V}, 2 \mathrm{hr}$ ) to nitrocellulose membranes using Mini TransBlot cell (Bio-Rad Laboratories, Richmond, CA) and Western transfer buffer (10X Tris/Glycine buffer, BioRad Laboratories, Richmond, CA) diluted with 20\% (v/v) methanol. Free binding sites were blocked in $5 \%(\mathrm{w} / \mathrm{v})$

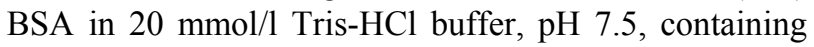
$150 \mathrm{mmol} / 1 \mathrm{NaCl}$ and $0.05 \%$ Tween 20 , for $1 \mathrm{~h}$. Primary antibodies against 12/15-lipoxygenase, or phosphorylated p38 MAPK, ERK, or SAPK/JNK were applied at $4^{\circ} \mathrm{C}$ overnight, after which secondary antibodies were applied at room temperature for $1 \mathrm{~h}$. After extensive washing, protein bands detected by the antibodies were visualized with the Amersham ECL ${ }^{\mathrm{TM}}$ Western Blotting Detection Reagent (Little Chalfont, Buckinghamshire, UK). Membranes previously probed for phosphorylated MAPKs were then stripped in the $25 \mathrm{mmol} / 1$ glycine- $\mathrm{HCl}$ buffer, $\mathrm{pH} 2.5$, containing $2 \% \mathrm{SDS}$, and reprobed with antibodies against total p38 MAPK, ERK, and SAPK/ JNK, respectively. Membranes previously probed for 12/ 15-lipoxygenase were stripped again and reprobed with $\beta$-actin antibody to confirm equal protein loading.

\subsubsection{ELISA 12(S)HETE Measurements}

For assessment of 12(S)HETE, sciatic nerve and spinal cord samples were homogenized on ice in $15 \mathrm{mM}$ Tris-HCI buffer $(1: 100 \mathrm{w} / \mathrm{v})$ containing $140 \mathrm{mM} \mathrm{NaCl}$, $\mathrm{pH} 7.6$, and centrifuged. 12(S)HETE was measured in supernatants with the 12(S)-hydroxyeicosatetraenoic acid [12(S)HETE] Enzyme Immuno Assay kit (Assay Designs, Ann Arbor, MI) according to manufacturer's instructions.

\subsection{Statistical Analysis}

The results are expressed as Mean \pm SEM. Data were subjected to equality of variance $\mathrm{F}$ test, and then to $\log$ transformation, if necessary, before one-way analysis of variance. Where overall significance $(p<0.05)$ was attained, individual between group comparisons for multiple groups were made using the Student-Newman-Keuls multiple range test. When between-group variance differences could not be normalized by log transformation (datasets for body weights and plasma glucose), the data were analyzed by the nonparametric Kruskal-Wallis oneway analysis of variance, followed by the Bonferroni/ Dunn test for multiple comparisons. Individual pair-wise comparisons in experiments 3 and 4 were made using the unpaired two-tailed Student's t-test or Mann-Whitney rank sum test where appropriate. Significance was defined at $\mathrm{p}<0.05$.

\section{RESULTS}

\subsection{Animal Experiments}

\subsubsection{Body Weights and Blood Glucose Concentrations}

The initial (prior to streptozotocin administration) body weights were similar in all experimental groups (Table 1). Weight gain during the 16-wk study was lower in both untreated and CDC-treated diabetic mice than in the non-diabetic control group. CDC treatment did not affect weight gain in either control or diabetic mice. Initial (after streptozotocin administration) non-fasting blood glucose concentrations were 2.0-fold and 1.9-fold higher in untreated and CDC-treated diabetic mice than in the control group. Hyperglycemia progressed with the prolongation of diabetes, and the differences between final blood glucose concentrations in both diabetic groups and non-diabetic controls exceeded 3-fold. CDC treatment did not affect non-fasting blood glucose concentrations in either non-diabetic or diabetic mice.

\subsubsection{2/15-Lipoxygenase Expression and 12(S)HETE Concentrations}

Sciatic nerve (Figures 1(a) and (b)) and spinal cord 
(Figures 1(d) and (e)) 12/15-lipoxygenase expression was increased by $40 \%$ and $57 \%$, respectively, in diabetic mice compared with controls. CDC treatment did not affect sciatic nerve and spinal cord 12/15-lipoxygenase expression in either control or diabetic mice. Sciatic nerve (Figure 1(c)) and spinal cord (Figure 1(f)) 12(S)HETE concentrations, a measure of 12/15-lipoxygenase activity, were increased by $223 \%$ and $48 \%$, respectively, in diabetic mice compared with controls. CDC treatment blunted diabetes-associated sciatic nerve and spinal cord 12(S)HETE accumulation.

\subsubsection{MAPK Expression in Sciatic Nerve and Spinal Cord}

Diabetic wild-type mice displayed $108 \%, 35 \%$, and $56 \%$ increases in sciatic nerve p38 MAPK (Figures 2(a),

Table 1. Initial and final body weights and blood glucose concentrations in control and diabetic mice maintained with and without CDC inhibitor treatment.

\begin{tabular}{cccc}
\hline \multirow{2}{*}{ Variable Group } & \multicolumn{2}{c}{ Body weight $(\mathrm{g})$} & Blood glucose $(\mathrm{mmol} / \mathrm{l})$ \\
\cline { 2 - 4 } & Initial & Final & Final \\
\hline Control & $24.6 \pm 0.4$ & $35.6 \pm 1.2$ & $8.2 \pm 0.6$ \\
Control + CDC & $25.1 \pm 0.3$ & $35.3 \pm 1.3$ & $8.6 \pm 0.3$ \\
Diabetic & $25.3 \pm 0.5$ & $27.9 \pm 0.6^{*}$ & $16.4 \pm 1.0^{*}$ \\
Diabetic + CDC & $25.2 \pm 0.6$ & $27.2 \pm 0.5^{*}$ & $16.0 \pm 1.2^{*}$ \\
\hline
\end{tabular}

Data are expressed as Means \pm SEM. $n=15$ per group. ${ }^{*} \mathrm{p}<0.01$ vs non-diabetic control group.

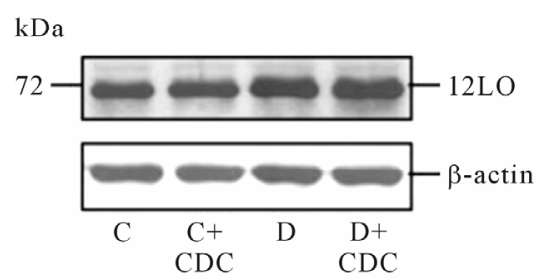

(a)

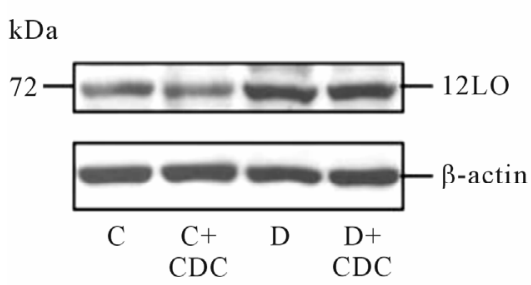

(d)

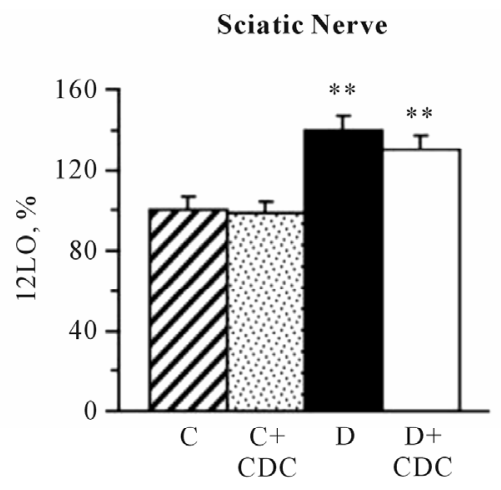

(b)

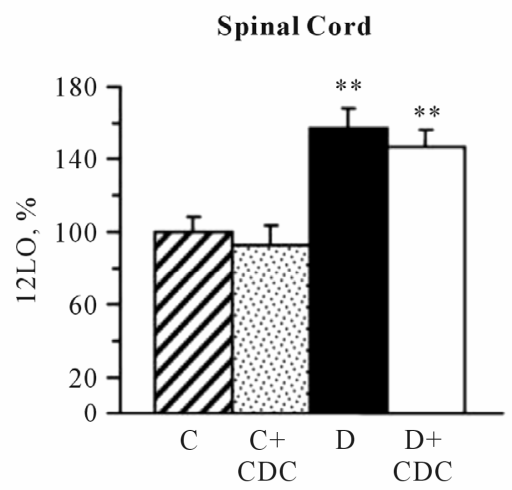

(e)

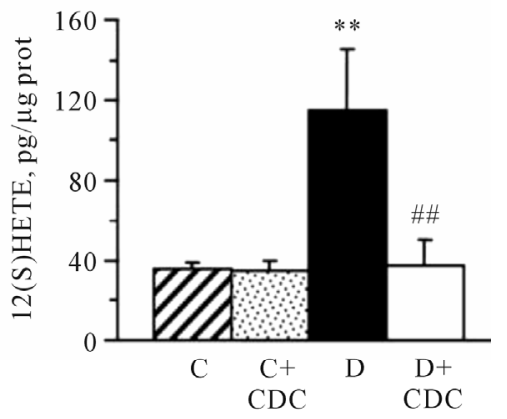

(c)

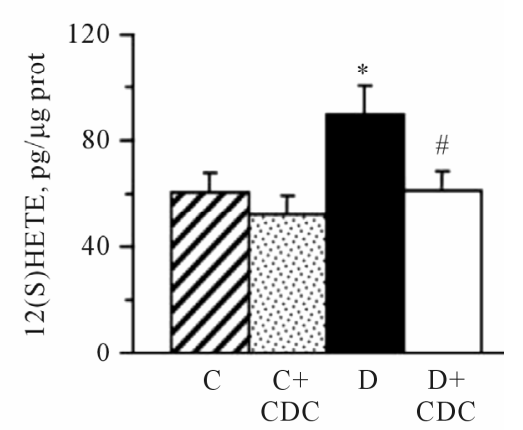

(f)

Figure 1. Representative Western blot analyses of 12/15-lipoxygenase expression (a), (d), 12/15-lipoxygenase protein contents (densitometry, \%, (b), (e)), and 12(S)HETE concentrations (c), (f) in the sciatic nerve and spinal cord of non-diabetic control and diabetic mice maintained with or without cinnamyl-3,4-dihydroxy- $\alpha$-cyanocinnamate treatment. C-control; D-diabetic; CDC-cinnamyl-3,4dihydroxy- $\alpha$-cyanocinnamate. Mean \pm SEM, $\mathrm{n}=6-11$ per group. ${ }^{*},{ }^{* *} \mathrm{p}<0.05$ and $<0.01$ vs non-diabetic control group. ${ }^{\#}$, ${ }^{\#} \mathrm{p}<0.05$ and $<0.01$ vs untreated diabetic group. 
(b)), ERK (Figures 2(d), (e)), and SAPK/JNK (Figures 2(g), (h)) phosphorylation, compared with the corresponding control group. Total p38 MAPK (Figures 2(a), (c)), ERK (Figures 2(d), (f)), and SAPK/JNK (Figures 2(g), (i)) levels were indistinguishable among the groups. CDC treatment did not affect the phosphorylation state of any of three MAPKs in non-diabetic mice. It reduced p38 and ERK phosphorylation by $58 \%$ and $23 \%$ (p < 0.05 vs corresponding untreated group for both comparisons), but did not affect SAPK/JNK phosphorylation, in diabetic mice. Spinal cord p38 MAPK (Figures 3(a), (b)), ERK (Figures 3(d), (e)) and SAPK/JNK (Figures 3(g), (h)) phosphorylation was elevated in both diabetic untreated mice, compared with the non-diabetic controls. Total p38 MAPK (Figures 3(a), (c)), ERK (Figures 3(d), (f)), and SAPK/JNK (Figures 3(g), (i)) levels were similar in control and diabetic mice maintained with or without CDC treatment. The 12/15-lipoxygenase inhibi- tor did not affect the phosphorylation state of any of three MAPKs in either non-diabetic or diabetic mice.

\subsection{Human Schwann Cells Experiment}

\section{MAPK Expression}

Phosphorylation of p38 MAPK (Figures 4(a), (b)), ERK (Figures 4(d), (e)), and SAPK/JNK (Figures 4(g), (h)) was increased by $47 \%, 38 \%$, and $95 \%$ in human Schwann cells cultured in $30 \mathrm{mM}$ glucose, compared with those cultured in $5.5 \mathrm{mM}$ glucose. Total p38 MAPK (Figure 4(c)), ERK (Figure 4(d)), and SAPK/JNK (Figure 4(i)) levels were indistinguishable among the experimental groups. CDC treatment did not affect levels of any total and phosphorylated MAPKs in human Schwann cells cultured in $5.5 \mathrm{mM}$ glucose, but completely prevented high glucose-induced increase in human Schwann cells p38 MAPK and ERK, but not SAPK/ JNK, phosphorylation.

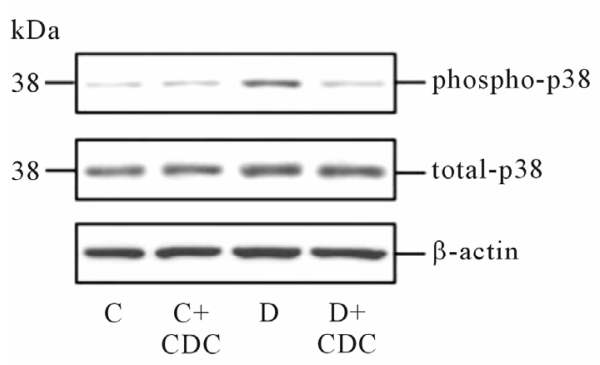

(a)

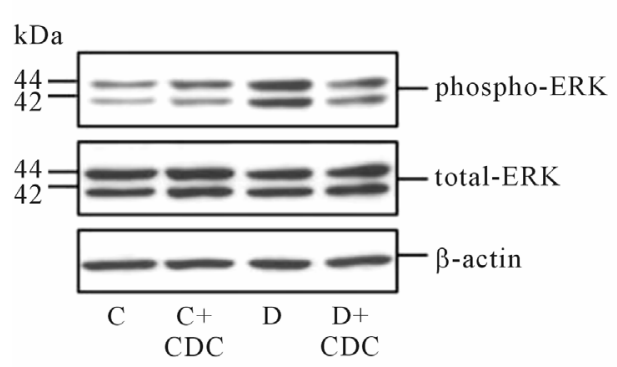

(d)

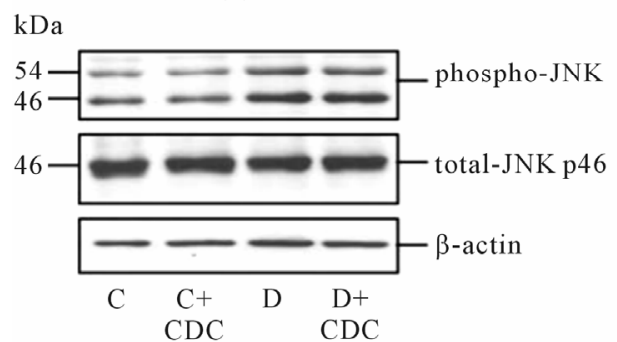

(g)

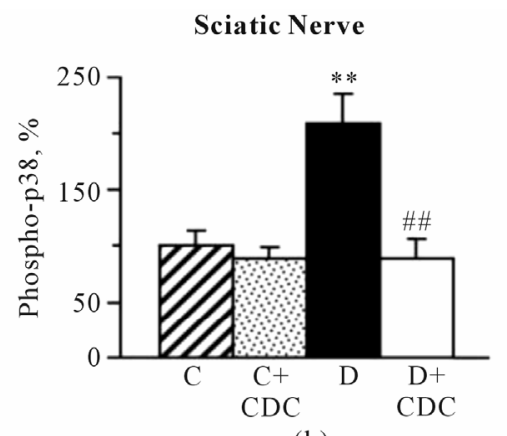

(b)

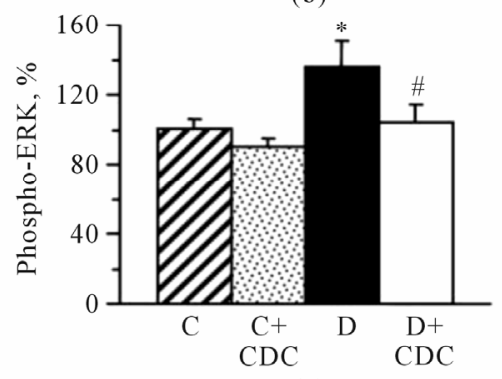

(e)

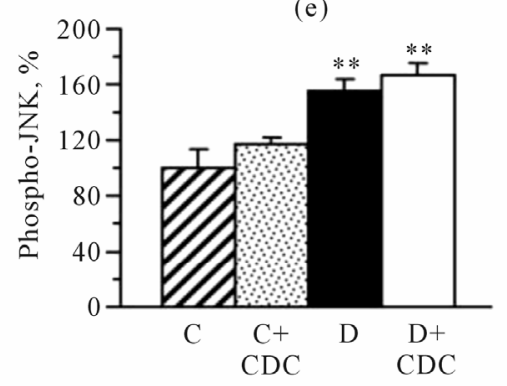

(h)

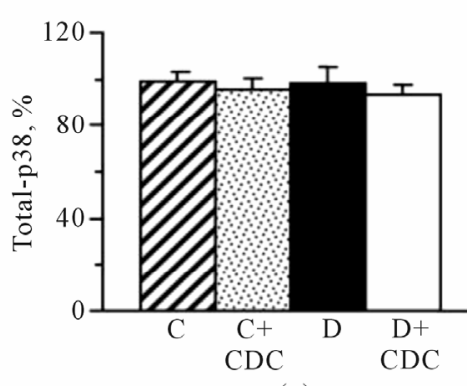

(c)

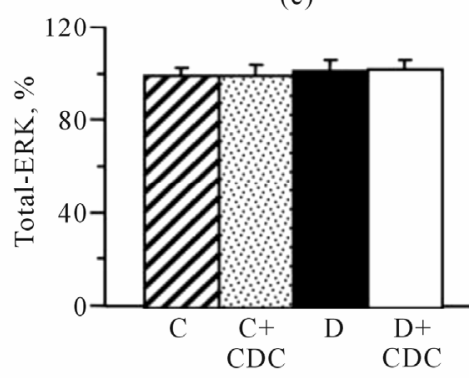

(f)

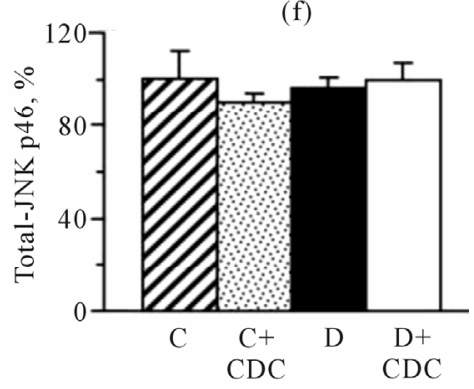

(i)

Figure 2. Representative Western blot analyses of phosphorylated and total p38 MAPK, ERK, and SAPK/JNK expression (a), (d), (g), and phosphorylated (b), (e), (h) and total (c), (f), (i) p38 MAPK, ERK, and SAPK/JNK protein contents (densitometry, \%) in the sciatic nerve of non-diabetic control and diabetic mice maintained with or without cinnamyl-3,4-dihydroxy- $\alpha$-cyanocinnamate treatment. C-control; D-diabetic; CDC-cinnamyl-3,4-dihydroxy- $\alpha$-cyanocinnamate. Mean \pm SEM, $\mathrm{n}=8-9$ per group. ${ }^{*},{ }^{* *} \mathrm{p}<0.05$ and $<0.01$ vs non-diabetic control group. ${ }^{\#, ~}{ }^{\#} \mathrm{p}<0.05$ and $<0.01$ vs untreated diabetic group. 


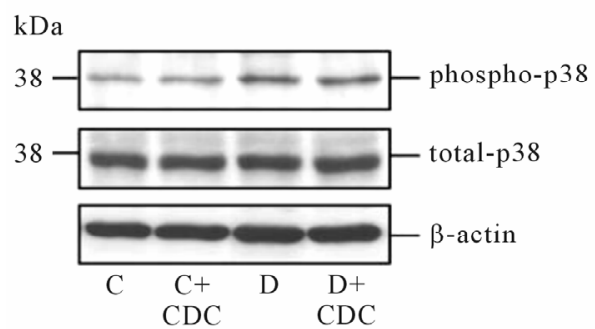

(a)

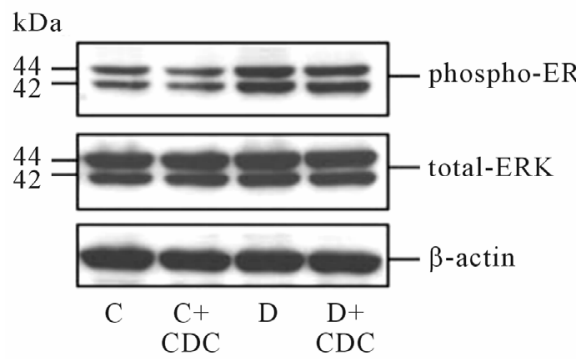

(d)

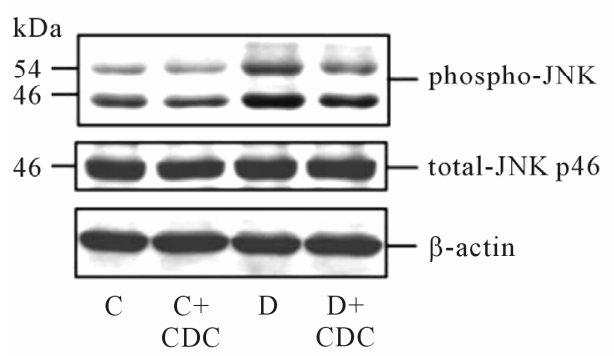

(g)

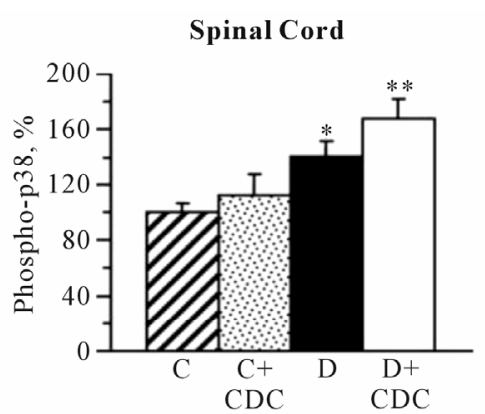

(b)

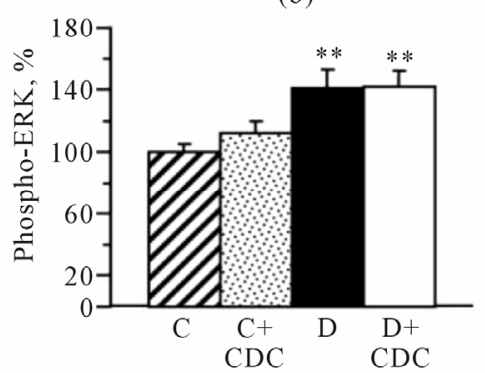

(e)

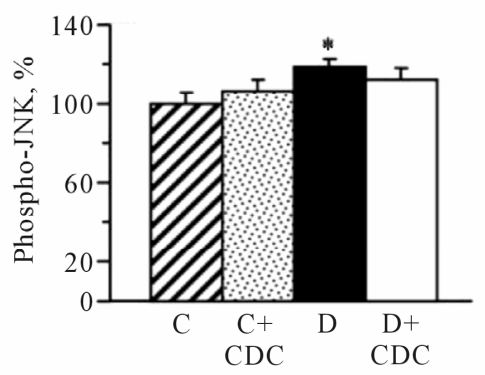

(h)

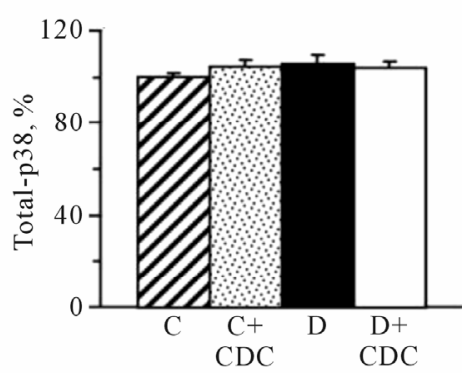

(c)

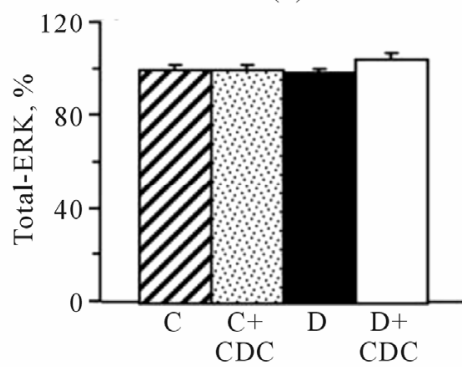

(f)

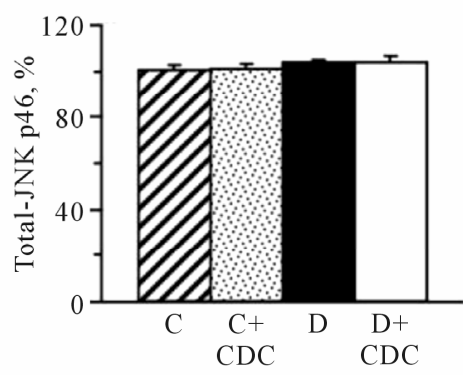

(i)

Figure 3. Representative Western blot analyses of phosphorylated and total p38 MAPK, ERK, and SAPK/JNK expression (a), (d), (g), and phosphorylated (b), (e), (h) and total (c), (f), (i) p38 MAPK, ERK, and SAPK/JNK protein contents (densitometry, \%) in the spinal cord of non-diabetic control and diabetic mice maintained with or without cinnamyl-3,4-dihydroxy- $\alpha$-cyanocinnamate treatment. C-control; D-diabetic; CDC-cinnamyl-3,4-dihydroxy- $\alpha$-cyanocinnamate. Mean \pm SEM, $n=6-8$ per group. ${ }^{*},{ }^{* *} \mathrm{p}<0.05$ and $<0.01$ vs non-diabetic control group.

\section{DISCUSSION}

The findings described herein indicate that pharmacological inhibition of 12/15-lipoxygenase suppresses diabetes-induced excessive p38 MAPK and ERK, but not SAPK/JNK, phosphorylation in mouse sciatic nerve. Furthermore, 12/15-lipoxygenase inhibition blunts high glucose-induced p38 MAPK and ERK, but not SAPK/ JNK, phosphorylation in human Schwann cells, thus suggesting the existence of the similar relationship between 12/15-lipoxygenase and MAPK in diabetic peripheral neuropathy in humans.

Evidence for the important role of the enzymes of arachidonic acid metabolism, cyclooxygenase-2 (COX-2, [23,39]) and 12/15-lipoxygenase [24,25], in functional, morphological, and biochemical abnormalities in diabetic peripheral neuropathy is emerging. Increased activity of COX-2 was implicated in motor nerve conduction velocity and sensory nerve conduction velocity deficits, oxidative stress, and inflammation associated with experimental diabetic peripheral neuropathy $[23,39]$, as well as in diabetic cardiac autonomic neuropathy and left ventricular dysfunction [40]. In our previous studies [24, $25]$, increased activity of 12/15-lipoxygenase was identified as an important contributor to diabetes-induced motor and sensory nerve conduction slowing, thermal and mechanical hypoalgesia, axonal atrophy of large myelinated fibers, and oxidative-nitrosative stress in peripheral nerve and spinal cord. Despite its clear role in oxidativenitrosative stress, 12/15-lipoxygenase activation was not involved in diabetes-associated reduction in intraepidermal nerve fiber density [24,25]. This makes exploration of the protective and pathobiochemical processes triggered through 12/15-lipoxygenase in tissue-sites for diabetic peripheral neuropathy particularly interesting.

Studies in animal models of diabetes-associated atherosclerosis and in vascular smooth muscle cells exposed to 
Human Schwann Cells

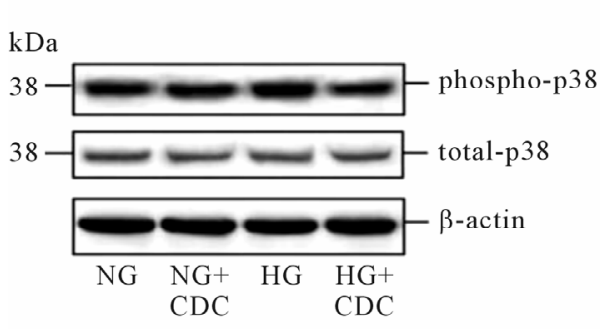

(a)

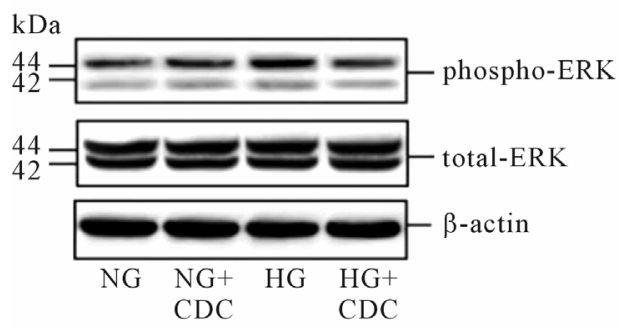

(d)

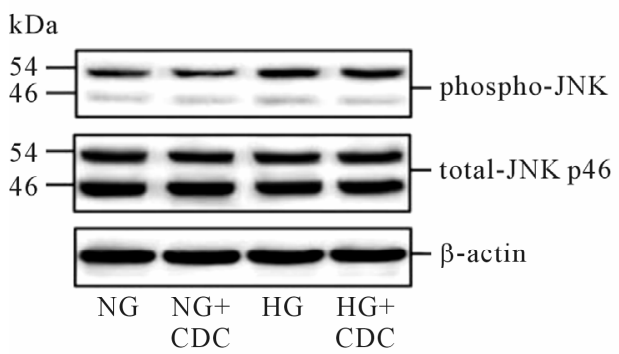

(g)

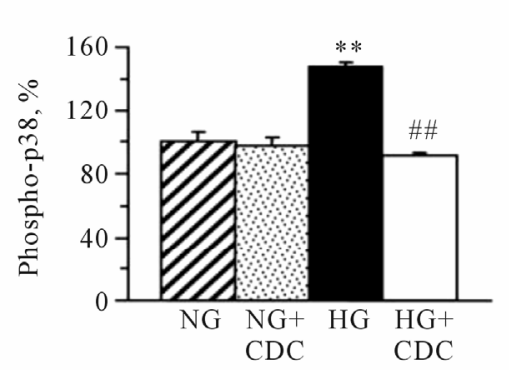

(b)

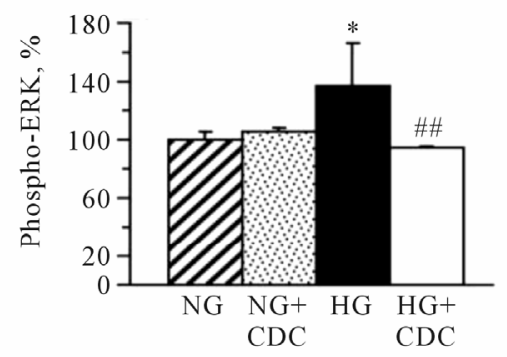

(e)

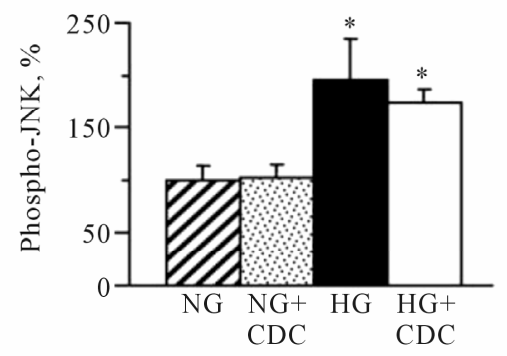

(h)

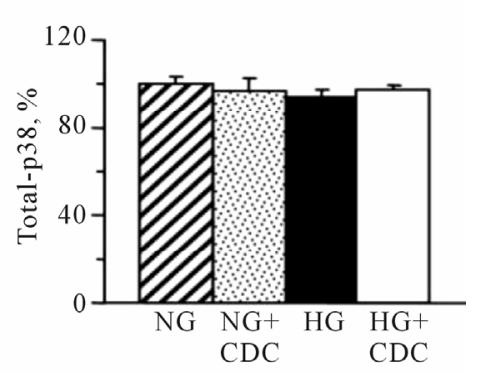

(c)

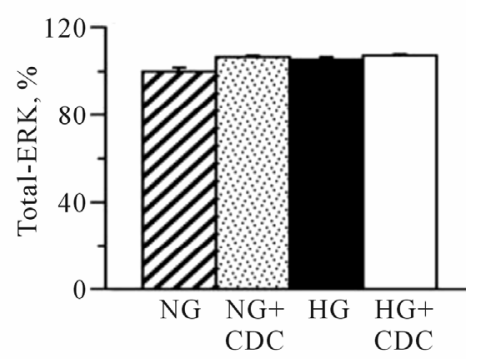

(f)

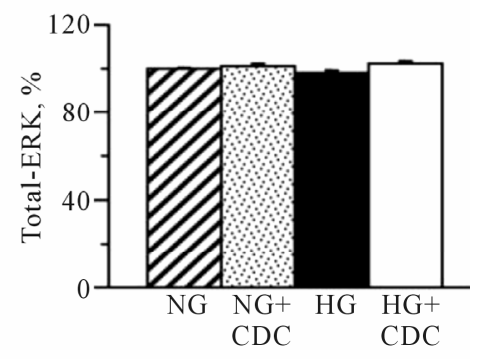

(i)

Figure 4. Representative Western blot analyses of phosphorylated and total p38 MAPK, ERK, and SAPK/JNK expression (a), (d), (g), and phosphorylated (b), (e), (h) and total (c), (f), (i) p38 MAPK, ERK, and SAPK/JNK protein contents (densitometry, \%) in human Schwann cells cultured in normal $(5.5 \mathrm{mM})$ or high $(30 \mathrm{mM})$ glucose with or without cinnamyl-3,4-dihydroxy- $\alpha$-cyanocinnamate. C-control; D-diabetic; CDC-cinnamyl-3,4-dihydroxy- $\alpha$-cyanocinnamate. Mean \pm SEM, $n=5-7$ per group. ${ }^{* * *}$ p $<0.05$ and $<0.01$ vs cells cultured in normal glucose. ${ }^{\#} \mathrm{p}<0.01$ vs cells cultured in high glucose without CDC.

the diabetic milieu [41-45] revealed that 12/15-lipoxygenase overexpression and activation is implicated in multiple biochemical changes including increased phosphorylation of ERK and p38 MAPK, Ras activation, cAMP response element-binding protein (CREB) phosphorylation, DNA-binding activity, and transactivation, overexpression of intercellular adhesion molecule-1, monocyte chemoattractant protein-1, and interleukin-6, activation of nuclear factor- $\kappa \mathrm{B}$, Src tyrosine kinase, focal adhesion kinase, and Akt, and histone H3-Lys-9/14 acetylation. The important role for 12/15-lipoxygenase in increased p38 MAPK, ERK, and CREB phosphorylation, and increased activator protein-1 and CREB DNA binding and transcriptional activities, as well as fibronectin overexpression has been identified in renal mesangial cells isolated from diabetic mice [46]. We have been particularly interested in the relationship between 12/15lipoxygenase and MAPKs, because both p38 MAPK
[26-28,47-49] and, recently, ERK [50,51], have been implicated in neuropathic changes in diabetes. In particular, increased p38 MAPK phosphorylation is involved in nerve conduction deficit [27], diabetic erectile autonomic neuropathy and vasculopathy [47], mechanical hyperalgesia [28,48], and tactile allodynia [49]. Increased ERK phosphorylation contributes to tactile allodynia [50] and mechanical hyperalgesia [51]. Furthermore, inhibition of p38 MAPK with its specific inhibittors SB239063 and SB203580 counteracted diabetesassociated GSH depletion in the peripheral nerve and COX-2, inducible nitric oxide synthase, and tumor necrosis factor- $\alpha$ overexpression in dorsal root ganglion neurons [28,52]. Our recent experiments [31] revealed that 12/15-lipoxygenase gene deficiency prevents diabetes-associated excessive p38 MAPK, ERK, but not SAPK/JNK phosphorylation, in peripheral nerve, and p38 MAPK, ERK, and SAPK/JNK phosphorylation in 
DRG. Interestingly, spinal cord p38 MAPK, ERK, and SAPK/JNK phosphorylation induced by diabetes, appeared independent of the LO mechanism. In the present study, similar findings in peripheral nerve and spinal cord were obtained with the 12/15-lipoxygenase inhibitor CDC. This is consistent with our previous results $[24,25]$ suggesting that $\mathrm{CDC}$, often considered as a relatively weak and non-specific12/15-lipoxygenase inhibitor [5355], can be used to dissect the role for leukocyte-type 12/15-lipoxygenase in diabetic peripheral neuropathy, and that the role for 12/15-lipoxygenase in MAPK activation varies in different tissues-12/15-lipoxygenase products have been found to cause SAPK/JNK activation in fibroblasts [56], but, apparently, this mechanism does not mediate high glucose-induced SAPK/JNK activation in human Schwann cells.

In conclusion, the present pharmacological study dissects the role for12/15-lipoxygenase in diabetes- and high glucose-induced MAPK activation in tissue-sites for diabetic peripheral neuropathy and human Schwann cells. They support interaction between the two mechanisms in the peripheral nerve, but not in spinal cord. The findings are relevant to understanding the mechanisms of diabetic peripheral neuropathy in humans, and suggest, that together with MAPK inhibitors, 12/15-lipoxygenase inhibitors can be used as pharmacological tool for inhibiting excessive MAPK phosphorylation in experimental, and, potentially, future clinical studies. In addition, our findings suggest that the 12/15-lipoxygenase inhibitor CDC can be used for dissection of the pathobiochemical mechanisms triggered by leukocyte-type 12/15-lipoxygenase, because the biochemical effects of CDC closely mimic those of leukocyte-type 12/15-lipoxygenase gene deficiency.

\section{ACKNOWLEDGEMENTS}

The study was supported in part by the National Institutes of Health Grants DK074517 (to I.G.O.), DK077141 (to I.G.O. and M.A.Y.), DK081147 (to I.G.O. and M.A.Y.), DK073990 (to M.A.Y.) and the American Diabetes Association Research Grant 7-08-RA-102 (to I.G.O.). The authors thank Dr.Rama Natarajan for valuable help with antibodies selections.

\section{REFERENCES}

[1] Boulton, A.J., Vinik, A.I., Arezzo, J.C., Bril, V., Feldman, E.L., Freeman, R., et al. (2005) Diabetic neuropathies: A statement by the American Diabetes Association. Diabetes Care, 28, 956-962. doi:10.2337/diacare.28.4.956

[2] Sinnreich, M., Taylor, B.V. and Dyck, P.J. (2005) Diabetic neuropathies. Classification, clinical features, and pathophysiological basis. Neurologist, 11, 63-79. doi:10.1097/01.nrl.0000156314.24508.ed

[3] Veves, A., Backonja, M. and Malik, R.A. (2008) Painful diabetic neuropathy: Epidemiology, natural history, early diagnosis, and treatment options. Pain Medicine, 9, 660674. doi:10.1111/j.1526-4637.2007.00347.x

[4] Tesfaye, S., Boulton, A.J., Dyck, P.J., Freeman, R., Horowitz, M., Kempler, P., et al. (2010) Diabetic neuropathies: Update on definitions, diagnostic criteria, estimation of severity, and treatments. Diabetes Care, 33, 2285-2293. doi: $10.2337 / \mathrm{dc} 10-1303$

[5] Yagihashi, S., Yamagishi, S.I., Wada, R.R., Baba, M., Hohman, T.C., Yabe-Nishimura, C., et al. (2001) Neuropathy in diabetic mice overexpressing human aldose reductase and effects of aldose reductase inhibitor. Brain, 124, 2448-2458. doi:10.1093/brain/124.12.2448

[6] Obrosova, I.G., Van Huysen, C., Fathallah, L., Cao, X.C., Greene, D.A. and Stevens, M.J. (2002) An aldose reductase inhibitor reverses early diabetes-induced changes in peripheral nerve function, metabolism, and antioxidative defense. The FASEB Journal, 16, 123-125.

[7] Ho, E.C., Lam, K.S., Chen, Y.S. and Yip, J.C., Arvindakshan, M., Yamagishi, S., et al. (2006) Aldose reductasedeficient mice are protected from delayed motor nerve conduction velocity, increased c-Jun NH2-terminal kinase activation, depletion of reduced glutathione, increased superoxide accumulation, and DNA damage. Diabetes, 55, 1946-1953. doi:10.2337/db05-1497

[8] Jack, M.M., Ryals, J.M. and Wright, D.E. (2011) Characterization of glyoxalase I in a streptozocin-induced mouse model of diabetes with painful and insensate neuropathy. Diabetologia, 54, 2174-2182. doi:10.1007/s00125-011-2196-3

[9] Bierhaus, A., Fleming, T., Stoyanov, S., Leffler, A., Babes, A., Neacsu, C., et al. (2012) Methylglyoxal modification of $\mathrm{Na}(\mathrm{v}) 1.8$ facilitates nociceptive neuron firing and causes hyperalgesia in diabetic neuropathy. Nature Medicine, 18, 926-933. doi: $10.1038 / \mathrm{nm} .2750$

[10] Bierhaus, A., Haslbeck, K.M., Humpert, P.M., Liliensiek, B., Dehmer, T., Morcos, M., et al. (2004) Loss of pain perception in diabetes is dependent on a receptor of the immunoglobulin superfamily. Journal Clinical Investigation, 114, 1741-1751.

[11] Cameron, N.E., Gibson, T.M., Nangle, M.R. and Cotter, M.A. (2005) Inhibitors of advanced glycation end product formation and neurovascular dysfunction in experimental diabetes. Annuals New York Academy Science, 1043, 784792. doi:10.1196/annals.1333.091

[12] Nagamatsu, M., Nickander, K.K., Schmelzer, J.D., Raya, A., Wittrock, D.A., Tritschler, H., et al. (1995) Lipoic acid improves nerve blood flow, reduces oxidative stress, and improves distal nerve conduction in experimental diabetic neuropathy. Diabetes Care, 18, 1160-1167. doi:10.2337/diacare.18.8.1160

[13] Cameron, N.E., Tuck, Z., McCabe, L. and Cotter, M.A. (2001) Effect of the hydroxyl radical scavenger, dimethylthiourea, on peripheral nerve tissue perfusion, conduction velocity and nociception in experimental diabetes. Diabetologia, 44, 1161-1169. doi:10.1007/s001250100626

[14] Coppey, L.J., Gellett, J.S., Davidson, E.P., Dunlap, J.A., Lund, D.D. and Yorek, M.A. (2001) Effect of antioxidant treatment of streptozotocin-induced diabetic rats on endoneurial blood flow, motor nerve conduction velocity, 
and vascular reactivity of epineurial arterioles of the sciatic nerve. Diabetes, 50, 1927-1937.

doi:10.2337/diabetes.50.8.1927

[15] Obrosova, I.G., Mabley, J.G., Zsengellér, Z., Charniauskaya, T., Abatan, O.I., Groves, J.T., et al. (2005) Role for nitrosative stress in diabetic neuropathy: Evidence from studies with a peroxynitrite decomposition catalyst. FASEB Journal, 19, 401-403.

[16] Lupachyk, S., Shevalye, H., Maksimchyk, Y., Drel, V.R. and Obrosova, I.G. (2011) PARP inhibition alleviates diabetes-induced systemic oxidative stress and neural tissue 4-hydroxynonenal adduct accumulation: Correlation with peripheral nerve function. Free Radical Biology Medicine, 50, 1400-1409. doi:10.1016/j.freeradbiomed.2011.01.037

[17] Goss, J.R., Goins, W.F., Lacomis, D., Mata, M., Glorioso, J.C. and Fink, D.J. (2002) Herpes simplex-mediated gene transfer of nerve growth factor protects against peripheral neuropathy in streptozotocin-induced diabetes in the mouse. Diabetes, 51, 2227-2232. doi:10.2337/diabetes.51.7.2227

[18] Bianchi, R., Buyukakilli, B., Brines, M., Savino, C., Cavaletti, G., Oggioni, N., et al. (2004) Erythropoietin both protects from and reverses experimental diabetic neuropathy. Proceedings National Academy Science, 101, 823-828. doi:10.1073/pnas.0307823100

[19] Nakamura, J., Kato, K., Hamada, Y., Nakayama, M., Chaya, S., Nakashima, E., et al. (1999) A protein kinase C-betaselective inhibitor ameliorates neural dysfunction in streptozotocin-induced diabetic rats. Diabetes, 48, 2090-2095. doi:10.2337/diabetes.48.10.2090

[20] Cameron, N.E., Cotter, M.A., Jack, A.M., Basso, M.D. and Hohman, T.C. (1999) Protein kinase C effects on nerve function, perfusion, $\mathrm{Na}(+), \mathrm{K}(+)$-ATPase activity and glutathione content in diabetic rats. Diabetologia, 42, 1120-1130. doi:10.1007/s001250051280

[21] Li, F., Drel, V.R., Szabó, C., Stevens, M.J. and Obrosova, I.G. (2005) Low-dose poly(ADP-ribose) polymerase inhibitor-containing combination therapies reverse early peripheral diabetic neuropathy. Diabetes, 54, 1514-1522. doi:10.2337/diabetes.54.5.1514

[22] Obrosova, I.G., Xu, W., Lyzogubov, V.V., Ilnytska, O., Mashtalir, N., Vareniuk, I., et al. (2008) PARP inhibition or gene deficiency counteracts intraepidermal nerve fiber loss and neuropathic pain in advanced diabetic neuropathy. Free Radical Biology Medicine, 44, 972-981. doi:10.1016/j.freeradbiomed.2007.09.013

[23] Kellogg, A.P., Wiggin, T.D., Larkin, D.D., Hayes, J.M., Stevens, M.J. and Pop-Busui, R. (2007) Protective effects of cyclooxygenase-2 gene inactivation against peripheral nerve dysfunction and intraepidermal nerve fiber loss in experimental diabetes. Diabetes, 56, 2997-3005. doi: $10.2337 / \mathrm{db} 07-0740$

[24] Stavniichuk, R., Drel, V.R., Shevalye, H., Vareniuk, I., Stevens, M.J., Nadler, J.L., et al. (2010) Role of 12/15lipoxygenase in nitrosative stress and peripheral prediabetic and diabetic neuropathies. Free Radical Biology Medicine, 49, 1036-1045. doi:10.1016/j.freeradbiomed.2010.06.016

[25] Obrosova, I.G., Stavniichuk, R., Drel, V.R., Shevalye, H., Vareniuk, I., Nadler, J.L., et al. (2010) Different roles of 12/15-lipoxygenase in diabetic large and small fiber peripheral and autonomic neuropathies. American Journal Pathology, 177, 1436-1447. doi:10.2353/ajpath.2010.100178

[26] Purves, T., Middlemas, A., Agthong, S., Jude, E.B., Boulton, A.J., Fernyhough, P., et al. (2001) A role for mitogen-activated protein kinases in the etiology of diabetic neuropathy. FASEB Journal, 15, 2508-2514. doi:10.1096/fj.01-0253hyp

[27] Price, S.A., Agthong, S., Middlemas, A.B. and Tomlinson, D.R. (2004) Mitogen-activated protein kinase p38 mediates reduced nerve conduction velocity in experimental diabetic neuropathy: Interactions with aldose reductase. Diabetes, 53, 1851-1856. doi:10.2337/diabetes.53.7.1851

[28] Cheng, H.T., Dauch, J.R., Oh, S.S., Hayes, J.M., Hong, Y. and Feldman, E.L. (2010) p38 mediates mechanical allodynia in a mouse model of type 2 diabetes. Molecular Pain, 19, 6-28.

[29] Stavniichuk, R., Drel, V.R., Shevalye, H., Maksimchyk, Y., Kuchmerovska, T.M., Nadler, J.L., et al. (2011) Baicalein alleviates diabetic peripheral neuropathy through inhibition of oxidative-nitrosative stress and p38 MAPK activation. Experimental Neurology, 230, 106-113. doi:10.1016/j.expneurol.2011.04.002

[30] Drel, V.R., Pacher, P., Stavniichuk, R., Xu, W., Zhang, J., Kuchmerovska, T.M., et al. (2011) Poly(ADP-ribose)polymerase inhibition counteracts renal hypertrophy and multiple manifestations of peripheral neuropathy in diabetic Akita mice. International Journal Molecular Medicine, 28, 629-635.

[31] Stavniichuk, R., Shevalye, H., Hirooka, H., Nadler, J.L. and Obrosova, I.G. (2012) Interplay of sorbitol pathway of glucose metabolism, 12/15-lipoxygenase, and mitogen-activated protein kinases in the pathogenesis of diabetic peripheral neuropathy. Biochemical Pharmacology, 83, 932-940. doi:10.1016/j.bcp.2012.01.015

[32] Askwith, T., Zeng, W., Eggo, M.C. and Stevens, M.J. (2012) Taurine reduces nitrosative stress and nitric oxide synthase expression in high glucose-exposed human Schwann cells. Experimental Neurology, 233, 154-162. doi:10.1016/j.expneurol.2011.09.010

[33] Roberts, P.J. and Der, C.J. (2007) Targeting the RafMEK-ERK mitogen-activated protein kinase cascade for the treatment of cancer. Oncogene, 26, 3291-3310. doi:10.1038/sj.onc. 1210422

[34] Lehmann, H.C. and Höke, A. (2010) Schwann cells as a therapeutic target for peripheral neuropathies. $\mathrm{CNS} \mathrm{Neu-}$ rology Disorders Drug Targets, 9, 801-816. doi:10.2174/187152710793237412

[35] Lehmann, H.C., Chen, W., Mi, R., Wang, S., Liu, Y., Rao, M., et al. (2012) Human Schwann cells retain essential phenotype characteristics after immortalization. Stem Cells Development, 21, 423-431. doi:10.1089/scd.2010.0513

[36] Obrosova, I.G., Drel, V.R., Pacher, P., Ilnytska, O., Wang, Z.Q., Stevens, M.J., et al. (2005) Oxidative-nitrosative stress and poly(ADP-ribose) polymerase (PARP) activition in experimental diabetic neuropathy: The relation is revisited. Diabetes, 54, 3435-3441. 
doi:10.2337/diabetes.54.12.3435

[37] Stevens, M.J., Li, F., Drel, V.R., Abatan, O.I., Kim, H., Burnett, D., et al. (2007) Nicotinamide reverses neurological and neurovascular deficits in streptozotocin diabetic rats. The Journal of Pharmacology and Experimental Therapeutics, 320, 458-464. doi:10.1124/jpet.106.109702

[38] Askwith, T., Zeng, W., Eggo, M.C. and Stevens, M.J. (2009) Oxidative stress and dysregulation of the taurine transporter in high-glucose-exposed human Schwann cells: Implications for pathogenesis of diabetic neuropathy. American Journal of Physiology Endocrinology and Metabolism, 297, 620-628. doi:10.1152/ajpendo.00287.2009

[39] Pop-Busui, R., Marinescu, V., Van Huysen, C., Li, F., Sullivan, K., Greene, D.A., et al. (2002) Dissection of metabolic, vascular, and nerve conduction interrelationships in experimental diabetic neuropathy by cyclooxygenase inhibition and acetyl-L-carnitine administration. Diabetes, 51, 2619-2628. doi:10.2337/diabetes.51.8.2619

[40] Kellogg, A.P., Converso, K., Wiggin, T., Stevens, M. and Pop-Busui, R. (2009) Effects of cyclooxygenase-2 gene inactivation on cardiac autonomic and left ventricular function in experimental diabetes. American Journal of Physiology Heart and Circulation Physiology, 296, 453461. doi:10.1152/ajpheart.00678.2008

[41] Reddy, M.A., Thimmalapura, P.R., Lanting, L., Nadler, J.L., Fatima, S. and Natarajan, R. (2002) The oxidized lipid and lipoxygenase product 12(S)-hydroxyeicosa-tetraenoic acid induces hypertrophy and fibronectin transcription in vascular smooth muscle cells via p38 MAPK and cAMP response element-binding protein activation. Mediation of angiotensin II effects. Journal of Biological Chemistry, 277, 9920-9928. doi:10.1074/jbc.M111305200

[42] Dwarakanath, R.S., Sahar, S., Reddy, M.A., Castanotto, D., Rossi, J.J. and Natarajan, R. (2004) Regulation of monocyte chemoattractant protein-1 by the oxidized lipid, 13-hydroperoxyoctadecadienoic acid, in vascular smooth muscle cells via nuclear factor-kappa B (NF-kappa B). Journal of Molecular and Cell Cardiology, 36, 585-595. doi:10.1016/j.yjmcc.2004.02.007

[43] Reilly, K.B., Srinivasan, S., Hatley, M.E., Patricia, M.K., Lannigan, J., Bolick, D.T., et al. (2004) 12/15-Lipoxygenase activity mediates inflammatory monocyte/endothelial interactions and atherosclerosis in vivo. The Journal of Biological Chemistry, 279, 9440-9450. doi:10.1074/jbc.M303857200

[44] Dwarakanath, R.S., Sahar, S., Lanting, L., Wang, N., Stemerman, M.B., Natarajan, R., et al. (2008) Viral vector-mediated 12/15-lipoxygenase overexpression in vascular smooth muscle cells enhances inflammatory gene expression and migration. Journal of Vascular Research, 45, 132-142. doi:10.1159/000109966

[45] Reddy, M.A., Sahar, S., Villeneuve, L.M., Lanting, L. and Natarajan, R. (2009) Role of src tyrosine kinase in the atherogenic effects of the 12/15-lipoxygenase pathway in vascular smooth muscle cells. Arteriosclerosis, Thrombosis and Vascular Biology, 29, 387-393.

doi:10.1161/ATVBAHA.108.179150
[46] Kim, Y.S., Reddy, M.A., Lanting, L., Adler, S.G. and Natarajan, R. (2003) Differential behavior of mesangial cells derived from 12/15-lipoxygenase knockout mice relative to control mice. Kidney International, 64, 17021714. doi:10.1046/j.1523-1755.2003.00286.x

[47] Nangle, M.R., Cotter, M.A. and Cameron, N.E. (2006) Correction of nitrergic neurovascular dysfunction in diabetic mouse corpus cavernosum by 338 mitogen-activated protein kinase inhibition. International Journal of Impotence Research, 18, 258-263. doi:10.1038/sj.ijir.3901414

[48] Daulhac, L., Mallet, C., Courteix, C., Etienne, M., Duroux, E., Privat, A.M., et al. (2006) Diabetes-induced mechanical hyperalgesia involves spinal mitogen-activated protein kinase activation in neurons and microglia via N-methyl-D-aspartate-dependent mechanisms. Molecular Pharmacology, 70, 1246-1254. doi:10.1124/mol.106.025478

[49] Du, Y., Tang, J., Li, G., Berti-Mattera, L., Lee, C.A., Bartkowski, D., et al. (2010) Effects of p38 MAPK inhibition on early stages of diabetic retinopathy and sensory nerve function. Investigative Ophthalmology \& Visual Science, 51, 2158-2164. doi:10.1167/iovs.09-3674

[50] Daulhac, L., Maffre, V., Mallet, C., Etienne, M., Privat, A.M., Kowalski-Chauvel, A., et al. (2011) Phosphorylation of spinal N-methyl-d-aspartate receptor NR1 subunits by extracellular signal-regulated kinase in dorsal horn neurons and microglia contributes to diabetes-induced painful neuropathy. European Journal of Pain, 15, 169.e1-169.e12.

[51] Tsuda, M., Ueno, H., Kataoka, A., Tozaki-Saitoh, H. and Inoue, K. (2008) Activation of dorsal horn microglia contributes to diabetes-induced tactile allodynia via extracellular signal-regulated protein kinase signaling. Glia, 56, 378-386. doi:10.1002/glia.20623

[52] Price, S.A., Gardiner, N.J., Duran-Jimenez, B., Zeef, L.A., Obrosova, I.G. and Tomlinson, D.R. (2006) Thioredoxin interacting protein is increased in sensory neurons in experimental diabetes. Brain Research, 1116, 206-214. doi:10.1016/j.brainres.2006.07.109

[53] Bürger, F., Krieg, P., Marks, F. and Fürstenberger, G. (2000) Positional- and stereo-selectivity of fatty acid oxygenation catalysed by mouse (12S)-lipoxygenase iso-enzymes. Biochemical Journal, 348, 329-335. doi:10.1042/0264-6021:3480329

[54] Gong, Y.Z., Ding, W.G., Wu, J., Tsuji, K., Horie, M. and Matsuura, H. (2008) Cinnamyl-3,4-dihydroxy-alpha cyanocinnamate and nordihydroguaiaretic acid inhibit human Kv1.5 currents independently of lipoxygenase. European Journal of Pharmacology, 600, 18-25. doi:10.1016/j.ejphar.2008.10.010

[55] Pergola, C., Jazzar, B., Rossi, A., Buehring, U., Luderer, S., Dehm, F., et al. (2011) Cinnamyl-3,4-dihydroxy- $\alpha$ cyanocinnamate is a potent inhibitor of 5-lipoxygenase. Journal of Pharmacology and Experimental Therapeutics, 338, 205-213. doi:10.1124/jpet.111.180794

[56] Wen, Y., Scott, S., Liu, Y., Gonzales, N. and Nadler, J.L. (1997) Evidence that angiotensin II and lipoxygenase products activate c-Jun $\mathrm{NH}_{2}$-terminal kinase. Circulation Research, 81, 651-655.doi:10.1161/01.RES.81.5.651 